\title{
Risk assessment for urban development of land subject to ground movements from abandoned old workings
}

\author{
J.D. St George The University of Auckland, New Zealand
}

\begin{abstract}
The presence of old abandoned workings underlying existing residential or planned residential development is a problem to land territorial authorities, developers and residents. Where the regulations controlling land development are managed on an effects-based approach, the hazards from abandoned underground workings present a particular problem to territorial authorities since they have overall control of development at any location. This in some way implies the acceptance of these risks and the acceptance of liability should anything occur. This paper will focus on the subsidence zone affected by surface intervention such as crownholes and the need to define the boundary of this zone in a practical engineering sense. A probabilistic framework is used to model the geological and mining uncertainties inherent in this type of analysis. The consequences of an event occurring and any remedial action taken are combined with the uncertainties to express the outcome in terms of risk. This approach is compared to other natural and manmade hazards influencing land development.
\end{abstract}

\section{Introduction}

\subsection{Background}

The presence of old abandoned workings underlying existing residential or planned residential development presents a problem to local territorial authorities (LTA), developers and residents. Where the workings are shallow particular problems arise and have been well documented (Wardell and Wood, 1965, Piggott and Eynon, 1978; Gray and Bruhn, 1982). Old coal workings usually dominate due to their widespread exploitation and the lateral extent of the workings as well as their proximity to urban development.

There have been many publications covering construction over abandoned workings (Cole, 1987; Bruhn et al., 1981; Healy and Head, 1984). From the research there is agreement about the primary hazards associated with abandoned old mine workings. These are:

- Crownholes/sinkholes - which are formed by the upward migration of a mining cavity to surface which results in a hole developing on surface.

- Subsidence fractures - which are caused by strain concentration along pre-existing features such as faults. They result in fault steps or fractures on surface.

- Trough subsidence - general settlement of the ground in the shape of a trough or basin around a collapsed zone of underground workings. Tension cracks may occur in areas of high tensile strains, but are more frequently associated with subsidence fractures.

- Mine entrances - the presence of old mine entrances like adits, shafts and drives presents a direct instability to surface. The main problems are uncertainty in location, possibility of collapse and the decay of any past stabilisation methods.

In most coalfields, seams will have been exploited from outcrop to relatively deep workings and the mining methods employed will vary somewhat depending on local conditions, historical factors and depth. In most parts of the world variants of the bord and pillar method have been applied.

In the shallow workings, where depth of cover is insufficient to prevent void migration from collapse workings reaching surface, crownholes can develop. As the depth of cover increases the void migration process is arrested by choke filling or the formation of a stable span. 
General trough type subsidence characterises both shallow as well as deep workings. In shallow areas, stress on pillars is low and extraction is usually high. Subsidence is characterised by very irregular - lumpy pothole depressions. As workings become deeper the subsidence trough takes on a more uniform bowl shape, with movements in towards the centre of the bowl and extending beyond the underground collapse zone. In deeper workings the subsidence is typified by smooth profiles similar to current longwall mining panels. The surface area of influence from the deeper workings will be much greater due to the angle of draw whereas fracturing and fault steps are much more prevalent at shallower depths.

The hazards associated with outcrop workings are highly localised and represent special treatment which has not been dealt with here. In most coalfields, faults, multiple seams, different mining methods and varying surface topography will have an influence, creating a complex interaction of possible subsidence zones.

Ground instability from abandoned workings can result many years after mining has ceased and hence is of ongoing concern with respect to surface land use. There is a clear distinction between events that impact on the surface directly such as crownholes, fractures and abandoned mine entrances (adits and shafts) and the general settlement associated with trough-like subsidence. The approach to land development in the crownhole zone takes on a different strategy since any structures would need special structural measures to mitigate against a crownhole collapse or have ground remediation to ensure voids are filled.

Land development in most countries is controlled by LTAs with a set of rules applied to different types of land usage. In New Zealand, LTAs are district and regional councils and they publish plans which clearly identify zoning and permitted activities in these zones. Both residential and industrial zoning criteria are based on the expectation that the landowner can develop their land in accordance with the rules laid down by the LTA at low risk. However, the regulations controlling development have shifted from a prescriptive approach to one based on effects. With respect to natural and artificial (man-made) hazards this presents a particular problem in that permitting land development to proceed implies there is an acceptance of increased risks. Along with this there is also the acceptance of liability should anything occur.

In most cases abandoned coal workings are close to existing urban regions through the historical development of the area. With demand for further development close to these areas there is increased pressure on the LTAs to grant permits to build closer to the abandoned workings. In some cases the land has been partially developed in the past, possibly commencing from the time of the coal mining. This presents the LTA with decisions on what to do with requests for extensions to existing structures as well as new construction on undeveloped sections.

There is tendency for the LTA to take a very conservative stance as the perceived consequences from collapse of abandoned workings are considered to be high when compared to other hazards such as slope failure and flooding. Other researchers have applied various risk assessment techniques to mine subsidence. Reddish et al. (1995) developed an integrated computer-based approach to assess surface structural damage from mine subsidence. A study by Cauvin et al. (2006) reported on the development of a technical risk prevention framework to manage post mining hazards in France. Stewart and Love (2005) considered a system for a risk-based approach to decision making under uncertainty with regard to pillar failure and then related to this to mine subsidence and damage to structures on surface.

This paper discusses the application of risk assessment techniques to areas of land development where there is a potential for surface damage due to delayed subsidence. The study will focus on the subsidence zone which lies just outside the areas that are affected by crownholes presenting a requirement to define this boundary in a practical engineering sense. This approach has been applied to several sites in a coalfield in Northland, New Zealand. Due to confidentiality concerns no site specific data is presented in this paper.

\section{Subsidence mechanisms}

\subsection{Crownholes}

In the assessment of ground instability above areas where crownhole collapse can occur, it is common practice to use the seam thickness or more correctly the worked thickness ' $t$ ' and assume the void from mining becomes choke filled as a result of collapse of the overburden strata. Approaches based on a simple one-dimensional model with the bulking factor have been developed to calculate a maximum height of 
collapse. Piggott and Eyon (1978) investigated a number of simple geometrical shapes (rectangular, wedge and conical) for the collapse chamber and calculated the height where the chamber becomes choke filled. They took a variety of bulking factors (30 to 50\%) considered typical for coal measure strata and calculated the heights of collapse. The heights of collapse ranged from 2 to $10 \mathrm{t}$. As a result they noted that "an a priori problem must be considered to exist where old mine workings are present at depths less than 10 times the extracted thickness below rockhead." In the UK this has become the de facto standard for shallow workings and the limitation for site investigations into mining. Recently, Fowell and Taylor (2007) have challenged this approach as being too limiting and not recognising other forms of subsidence.

It is interesting to note that Garrard and Taylor (1988), from observations of collapse workings in open pit high walls, found no direct relationship between seam thickness and height of collapse, however, the envelope enclosing the observed collapses was $6.5 \mathrm{x}$ seam thickness. Not all the observed collapses were choke filled and, therefore, further collapse was possible. By extrapolating the void migration to completely fill the remaining space, Garrard and Taylor predicted a theoretical height of collapse of $9.8 \times$ seam thickness. This is only pertinent for the UK coalfields where the observations were made but does give some confidence to areas where the $10 \mathrm{t}$ multiplier has been used.

\subsection{Trough subsidence}

Trough subsidence over abandoned workings will be caused by the general collapse of the workings as a result of pillar failure, pillar punching or roof failure.

- Pillar failure - occurs when the strength of one or more pillars is exceeded. Over time, pillars may deteriorate due to weathering/erosion processes potentially, until they are unable to support the loading from the superincumbent strata. At this stage load is transferred to adjacent pillars which will also have experienced deterioration. This can continue until an area collapses. The likelihood of this type of failure is influenced by the strength of the coal, pillar geometry and weathering/erosion processes.

- Pillar punching - where weak horizons are present in either the roof or the floor of the coal seam, increased loading above or below the pillar can cause these soft horizons to fail. The failed material then moves into the void created by mining. Essentially, settlement is controlled by the strength and thickness of the weak layer.

- Roof failure - in this mechanism the immediate roof collapses into the mining void. Successive upward collapse continues until a stable span is reached or the caved material supports the superincumbent strata.

In bord and pillar workings, the magnitude of the trough subsidence is more dependent on the void space to be filled than by the mode of failure.

\section{$3 \quad$ Hazard assessment}

As with all problems related to ground instability it is important to go through a number of phases of investigation in order to fully develop a systematic approach towards evaluating the hazard. There are four broad investigation phases as listed below:

- Initial data gathering desk and field studies.

- Hazard evaluation.

- Assessment.

- Design and implementation.

The data gathering phase is particularly important and should include a thorough investigation of the historical mining and geology of the site. Information is compiled from many sources including: archived mining records, old mine plans, topographic surveys, aerial photographs, geological records and maps. Background data from other sources such as interviews with miners or old newspaper articles can also provide valuable insight into mining conditions and events. Field mapping and identification of surface 
features, such as adits or shafts, is an essential component of the site investigation work. Further study might indicate a need for further field work such as drilling, geophysical (resistance, seismic, gravity) or ground radar. A comprehensive case study of an investigation into abandoned workings under Newcastle is given by Hawkins (2005) which shows the significant detail required for such an investigation.

Once this information has been assembled, the area under study can be examined in detail. A compilation of all the available mining and geological information should be transferred to plans plotted to a convenient scale showing mine workings, seam floor contours, overburden thicknesses and subsidence features such as crownhole collapses and fractures. This becomes the base plan for the study.

\subsection{Hazard evaluation - crownholes}

It is important to collect and collate as much data as possible, since it is only possible to apply a risk-based approach where there is sufficient information on the geological and mining factors at the site. A risk-based approach is not recommended at sites where there is little or no information on the mining activity, since a formal treatment of risk, which deals with uncertainty and variability, cannot take into account unknowns.

For a risk assessment approach the preliminary stage is to make an estimate of the probability of occurrence and then to assess the consequence of the event. In the case of a crownhole, the probability will depend on the mechanism of failure to surface. In terms of the possible paths to long-term stability the void caused by mining must either choke fill or form a stable arch. There is also a need to consider whether this probability will change with time. This would entail an assessment of the effects of, for example, erosion on the collapsed material or of groundwater changes in the old workings as well as weathering processing. This is a significant factor as the design life for a residential development is at least 50 years and in some cases much longer.

There is also the further consideration in that for old mine workings, where the potential for crownhole collapse exists, there are only a finite number of places for collapse to occur. In a probabilistic framework, the overall probability of a crownhole collapse will be reducing, since they are one-time events if only new collapses are considered rather than reactivation of old collapses. The timeframe here could be several hundred years for complete stabilisation, therefore possibly taking in several cycles of development.

The first step in the process is to differentiate between the crownhole potential and trough type subsidence. A reasonable starting point is to assume $10 \mathrm{t}$ where $\mathrm{t}$ is the best estimate of the worked thickness. By plotting this line onto the plan with the existing crownholes any discontinuities can be easily identified.

The data collection needs to provide enough information for estimates of the average, lower and upper bound values of the worked thickness $(t)$ and bulking factors $\left(\mathrm{B}_{\mathrm{F}}\right)$ at a particular location. Using a simple onedimensional model, estimates of the potential caving height $\left(\mathrm{h}_{\mathrm{C}}\right)$ to choke fill the opening can be made. The variability of the caving height can be determined by using either Monte Carlo simulation, or second moment approximations based on the point estimation method (Hoek, 2007). Monte Carlo analysis is relatively easy to implement in packages such as @RISK which runs in a spreadsheet but it requires a number of assumptions regarding the probability density functions that model the variability of the random variables. A simple triangular distribution is usually sufficient with data comprising of means, upper and lower bounds. Output from this type of analysis is in the form of a distribution from which the mean and standard deviation can be found. The point estimation method can also easily be implemented in a spreadsheet or by hand calculation and only provides the moment estimates.

A crownhole index (CI) based on a similar approach to Richards et al. (2002) is defined as:

$$
\mathrm{CI}=\mathrm{h}_{\mathrm{S}} / \mathrm{h}_{\mathrm{C}}
$$

where:

$\mathrm{h}_{\mathrm{S}}=$ the height of rock cover from the seam floor.

$\mathrm{h}_{\mathrm{C}}=$ the height of caving.

A CI $>1$ is stable while $\mathrm{CI}<1$ is indicative a crownhole will or has formed.

The height of rock cover $\left(\mathrm{h}_{\mathrm{S}}\right)$ can be taken as either a single, representative deterministic value or treated as a variable possessing upper and lower bounds. In either approach the variability in the CI can be determined 
using the Monte Carlo or point estimate methods as described previously to yield an estimate of the mean and standard deviation of CI. From these the reliability index $\beta$ of the CI can be determined:

$$
\beta=\frac{\bar{C} \bar{I}-1}{\sigma_{C I}}
$$

where:

$\begin{array}{lll}\bar{C} \bar{I} & = & \text { the mean crownhole index. } \\ \sigma_{C I}= & \text { the standard deviation of the CI. }\end{array}$

The reliability index is a measure of the distance (in units of standard deviation) that the mean is from the failure condition. A value of $\beta=1$ is approximately equivalent to a probability of $15 \%$, assuming that CI can be described by a normal distribution, while a value of 2 is around $2.5 \%$.

The mean values of the CI can be calculated at locations where actual crownholes have developed. In some sense this gives a calibration to values used in the analysis. Any outliers or anomalies should be investigated thoroughly. Specifically, if there are existing or past crownholes that are outside the $10 \mathrm{t}$ line, it is probable that there have been cave-ins during mining which have been cleared away or that weak material in the overlying strata has flowed into the workings. If, on the other hand, these crownhole areas have developed after the cessation of mining then there is clearly a collapse process that needs to be investigated and identified.

In areas where the $\mathrm{CI}$ is below one, and there are no observations of collapses, it is probable that there is a strong layer arresting the collapse process. Open-hole probe drilling can be a cost-effective way of investigating if competent units are present.

Since the crownhole index is defined as the ratio of available height to estimated caving height, the CI can be compared to a factor of safety, where typically resisting forces are balanced with mobilising forces. In both cases a value of unity indicates limiting conditions. Values greater than one provide some measure of safety. As an example, New Zealand guidelines specify that a factor of safety of 1.2 under extreme groundwater conditions be applied to potential slope failure affecting residential development. This implies the strength exceeds the destabilising loads by $20 \%$. If this is related to a reliability approach with the variability in the input parameters factored into the analysis, the reliability index for the slope can be determined. Assuming the main variability is in the shear strength determination then for a slope with a factor of safety of 1.2 , $\beta$ ranges from 1.2 to 1.6 using published variations of shear strength parameters.

The reliability index essentially measures the level of confidence in the result. The higher the value, the greater the confidence. Therefore, for slope stability in residential development an acceptable level of confidence is expressed as a reliability index of between 1.2 and 1.6. Demanding the same level of confidence for evaluating the possibility of a crownhole collapse would be consistent if the consequences of the events were relatively similar. It could be argued that the consequence of a crownhole collapse is less severe than slope failure due to their highly localised occurrence and influence. However, this would depend on a case-by-case comparison which is not relevant here. For the approach presented, it is sufficient to accept that the consequences of crownhole collapse are similar to or less severe than slope failure.

Therefore, by taking the same value of $\beta$ for slope failure and crownhole collapse, a translation at the same degree of confidence is mapped. A contour line representing the CI for $\beta=1.6$ (a conservative estimate) provides a demarcation to the crownhole zone which is consistent with slope failure and other geotechnical hazards. This $\beta$ value could be refined to suit local conditions and practices, if desired.

\subsection{Hazard evaluation - trough subsidence}

In determining the potential for trough subsidence, the approach advocated by Marino (1990) was modified to provide input into a risk matrix for land development.

Working from the base plan, the crownhole zone is defined as outlined above and is excluded from the development area. For all other areas the hazards are characterised in terms of their effect and prediction and these are listed below in order of severity with respect to land development. 
- Mine entrances and shafts.

- Underground faults connected to the workings - possibility of strain accumulation resulting in fracturing or fault steps.

- Surface strains - tensile and compressive.

- Crownholes.

Crownholes are included on this list since there will be a residual probability of occurrence although very small. Initially all the mine entrances and shaft areas were delimited with appropriate buffers and were excluded. In the second phase of the analysis a level of confidence was put on all the mine plan data from pillar dimensions, underground fault positions, and multi-seam workings to the likelihood of pillar robbing. These factors varied from 1 - absolute certainty, for example where a shaft is marked on a plan and its position has been identified on the site, to around 0.1 where there is a high degree of uncertainty. An example of where there is a high degree of uncertainty would be where two seams are present yet workings are only recorded in one seam. Uncertainty arises from the possibility of workings in the other seam.

At this stage the fault data were compiled in terms of orientation inferred from plans and possible dip angles which were estimated from actual fractures, drill-hole logs and regional data. The estimated position of the surface expression of the fault trace could then be marked on the plans. From this position a series of corridors either side of the estimated position were constructed based on the error bands in the dips. Three dip ranges were selected to model the likely, possible and unlikely categories in dip error. These were factored to include the effect of depth. In this particular coalfield it was subjectively assessed that faults mapped in workings at depths less than $45 \mathrm{~m}$, there was a high likelihood of fracturing. For depths below $100 \mathrm{~m}$, subsidence fracturing was assessed as very unlikely.

In order to determine the subsidence profile for possible future collapses over old mine workings a technique using influence functions developed by St George (2002) was applied. This method is based on a semi-empirical technique which integrates the subsidence effects of small extraction elements at a point on the surface. It had been modified to predict settlements and strains over partial extraction panels and bord and pillar workings based on percentage extraction. Independent of the influence function, two field parameters, the subsidence factor and the angle of draw (limit angle) are required. These have been estimated from cases studies of previous subsidence events or experiences with current mining in similar geology.

Potential development locations were defined by a square foundation footprint and then settlement and strains calculated at the corners for various collapse scenarios of underground workings. These zones started from subcritical and extended to critical or to the boundaries of the worked area in accord with the method proposed by Marino (1990). In New Zealand, most coalfields are heavily faulted and therefore extraction areas are relatively small and fault controlled. The influence technique is efficient at processing this information since the effect of several adjacent potential collapses can be modelled in on run.

The output from the subsidence model comprises of maximum compressive and tensile strains at the potential development sites. A further parameter was introduced which assessed the likelihood of each collapse area. This was factored with the level of confidence of the input variables to produce one of three likelihood classes (high, moderate or low). This information was collated into a risk matrix, part of which is shown in Table 1.

The rationale behind selecting a strain of $4 \mathrm{~mm} / \mathrm{m}$ was from local practice. Expansive soils in the region are known to shrink and swell and the design criteria are often set at $4 \mathrm{~mm} / \mathrm{m}$ for foundations. It was hence relatively easy for the structural engineers to design foundations to cope with this order of strains and also be quite cost effective. 
Table 1 Risk matrix

\section{Likelihood}

\begin{tabular}{|c|c|c|c|}
\hline Hazard & High & Moderate & Low \\
\hline $\begin{array}{l}\text { Mine entrances/ } \\
\text { shafts }\end{array}$ & Exclusion zone & Exclusion zone & Some infrastructure \\
\hline \multirow{3}{*}{$\begin{array}{l}\text { Fault trace } \\
\text { underground }\end{array}$} & Expected dip $\pm 15^{\circ}$ & Expected dip $\pm 20^{\circ}$ & Expected dip $\pm 25^{\circ}$ \\
\hline & No dwellings & No dwellings & No dwellings \\
\hline & Avoid services & Services/to fault & $\begin{array}{l}\text { Roads and secondary } \\
\text { structures }\end{array}$ \\
\hline \multirow[t]{3}{*}{ Strains single seam } & $>4 \mathrm{~mm} / \mathrm{m}$ & $>4 \mathrm{~mm} / \mathrm{m}$ & $>4 \mathrm{~mm} / \mathrm{m}$ \\
\hline & No dwellings & No dwellings & No dwellings \\
\hline & & Services & Infrastructure and services \\
\hline \multirow[t]{2}{*}{ Strains single seam } & 1 to $4 \mathrm{~mm} / \mathrm{m}$ & 1 to $4 \mathrm{~mm} / \mathrm{m}$ & 1 to $4 \mathrm{~mm} / \mathrm{m}$ \\
\hline & $\begin{array}{l}\text { Dwellings special } \\
\text { footings }\end{array}$ & $\begin{array}{l}\text { Dwellings special } \\
\text { footings }\end{array}$ & $\begin{array}{l}\text { Dwellings special } \\
\text { footings }\end{array}$ \\
\hline
\end{tabular}

\section{Discussion}

The approach put forward in this paper shows how a risk analysis can be applied to identify certain regions affected by old mine workings particularly related to crownhole collapse and subsidence. The level of risk for crownhole collapse was selected so that it was comparable with slope stability, a common geotechnical hazard. The effect of settlements and strains were evaluated to guide planning and design for development to meet acceptable levels of risk. There are a number of assessments required during the process which tend to limit the system. However, with clear communication, these qualitative aspects can be easily updated.

It also provides an opportunity to carry out further assessment into the economic consequences of proposed development. By taking a number of scenarios of possible areas of collapse, the expected damage to properties, infrastructure and services can be estimated. In addition the cost of repair and remediation of these facilities and structures can be determined. From this a measure of the overall exposure for the development can be gained. This can be very useful information for the LTA in considering the permitting of such developments.

\section{References}

Bruhn, W., Magnuson, M.O. and Gray, R. (1981) Subsidence over abandoned mine in the Pittsburgh Coalbed, In Proceedings 2nd International Conference on Ground movements and Structures, J. Geddes (ed), Pentech Press, London, pp. 142-156.

Cauvin, M., Verdel, T., Salmon, R. and Didier, C. (2006) Mapping expert uncertainties or confidence level in mining risk prevention plans, International Conference on Geohazards, ECI, F. Nadim, R. Pöttler, H. Einstein, H. Klapperich and S. Kramer (eds), Lillehammer, Norway, paper number 31.

Cole, K.W. (1987) Building over abandoned shallow mines, Ground Engineering, May, pp. 14-30.

Fowell, R.J. and Taylor, J.A. (2007) Mining instability and the misuse of the 10-times-seam thickness rule, 11th Congress of International Society for Rock Mechanics, ed. L. Ribeiro e Sousa, C. Olalla and N. Grossman, pp. 63-67.

Gray, R.E. and Bruhn, R.W. (1982) Subsidence above abandoned coal mines, in State-of-the-art of Ground Control in Longwall Mining and Mining Subsidence, Chapter 23 Subsidence planning and control, AIME, $19 \mathrm{p}$.

Hawkins, G.C. (2005) Geotechnical investigation of the abandoned mine workings under Newcastle, Australian Geomechanics, Vol. 40, No. 1, pp. 61-78.

Healy, P.R. and Head, J.M. (1984) Construction over abandoned mine workings, CIRIA Special publication, 32, PSA Civil Engineering Technical Guide, Vol. 34, 95 p.

Hoek, E. (2007) Practical Rock Engineering, viewed 29 May 2009 http://www.rocscience.com/hoek/pdf/Practical_Rock_Engineering.pdf, p. 134. 
Marino, G.G. (1990) Siting of a prison complex above abandoned underground coal mine, Journal Geotechnical and Geo-Environmental Engineering, American Society of Civil Engineers, 124, 10, pp. 954-964.

Piggott, R.J. and Eynon, P. (1978) Ground movements arising from the presence of shallow mine workings, Proceedings International Conference of Large Ground Movements and Structures, J. Geddes (ed), Pentech Press, London, pp. 745-780.

Reddish, D.J., Yao, X.L. and Dunham, R.K. (1995) Risk assessment of surface structural damage due to mining subsidence - and integrated computer-based approach, Trans IMM, Sect A, 104, pp. A139-A143.

Richards, L.R., Mazengarb, C., Beetham, R., Brathwaite, R. and Smith, W. (2002) Waihi underground mine workings, Stage II investigations, IGNS Report 2002/46, 111 p.

Stewart, M.G. and Love, A. (2005) Uncertainty, economic risk analysis and risk acceptance criteria for mine subsidence, Australian Geomechanics, Vol. 40, No. 1, pp. 79-90.

St George, J.D. (2002) Surface subsidence modelling for prediction of settlements from thick seam partial extraction, AusIMM Conference, Auckland, 6/02, pp. 407-412.

Wardell, K.W. and Wood, J.C. (1965) Ground instability arising from old shallow mine workings, Proceedings of the Midland Soil Mechanics and Foundation Society, paper number 36, 7, pp. 5-30. 